\title{
El pluralismo en el Estado plurinacional, redundancia o pertinencia*
}

\author{
Pluralism in the Plurinational State, \\ Redundancy or Fitness
}

Fecha de recepción: 22 de agosto de 2010

Fecha de aprobación: 18 de noviembre de 2010

\author{
Rosembert Ariza Santamaría ${ }^{*}$
}

\section{Resumen}

Latinoamérica, en general, vive hoy una realidad política donde aparecen nuevas paradojas. Tal vez una de la más compleja es la de la aplicación del pluralismo en un Estado que se autodenomina "plurinacional". El estudio de esta paradoja es el cometido del presente texto, en el marco de las nuevas constituciones y de manera muy puntual en la Constitución boliviana. Además, se pretende responder a las siguientes dos preguntas: ¿Qué implicaciones tiene en el Estado pluricultural la diversidad? y ¿ es pertinente el pluralismo en el marco de un Estado plurinacional?

Palabras clave: diversidad, pluralismo, pluriculturalidad, plurinacionalidad, Estado plurinacional, pertinencia.

\section{Abstract}

Latin America in general today lives a paradoxia political reality. The most complex paradox is the implementation of pluralism in a state that calls itself plurinational. This study examines this type of state, under the new constitutions and precisely in the Bolivian Constitution. It also seeks to answer to the following two questions: what are the implications of a state pluricultural diversity? and is it pluralism relevant in a plurinational state?

Key words: diversity, pluralism, multiculturalism, plurinationality, plurinational state, relevance

* Ponencia presentada en el Seminario Estado de Derecho y Derechos Humanos en Bolivia, realizado en Sucre Bolivia el 18 y 19 de octubre de 2010.

** Abogado, doctor en Sociología Jurídica. Docente Investigador de la Universidad Nacional de Colombia y de la Universidad Santo Tomás. Experto en derechos humanos y administración de justicia. Miembro de PRUJULA y RELAJU y consultor IIDH. Correo electrónico: arosembert@yahoo.es 
Un Estado que se presuma democrático debe preservar todas las formas de pluralismo. El llamado Estado plurinacional es el más Ilamado a la realización del pluralismo en todas sus manifestaciones, los límite que ponga al pluralismo determinará que tan democrático es.

Este asunto se constituye en una paradoja que se define como una idea extraña, opuesta a lo que se considera verdadero a la opinión general. Así lo establece el diccionario de la Real Academia de la Lengua Española que encaja en el estudio que nos ocupa alrededor del pluralismo en un Estado plurinacional, pues no se subsume el pluralismo en la pluriculturalidad. He aquí la paradoja del constitucionalismo que la jurisprudencia, tanto ecuatoriana como boliviana, que está por venir, tendrá que dilucidar.

Sabemos que desde principios de los años noventa varios países de la región como Brasil, Colombia, Perú, Venezuela, Ecuador y Bolivia establecieron el reconocimiento constitucional del pluralismo. Dicho reconocimiento se basó, inicialmente, en una perspectiva multicultural que se erige sobre la base de la diversidad. Sin embargo, los tribunales constitucionales impulsaron lo que el profesor Boaventura de Sousa Santos denominó el "constitucionalismo transformador". Este constitucionalismo avanza en una perspectiva intercultural que en efecto desencaja la fórmula del Estado Nación.

Sobre este aspecto, Luis Villoro señala que el Estadonación moderno impone un orden sobre la compleja diversidad de las sociedades que la componen. En la heterogeneidad de la sociedad debe establecerse la uniformidad de una legislación general, de una administración central, de una cultura nacional válida para todos y de un poder único. De ahí que el Estado debe borrar la multiplicidad de las sociedades sobre las que se impone y se establece sobre ellas un solo orden. La ideología del Estado-nación moderno es el nacionalismo, el cual se puede caracterizar por dos ideas centrales:
1. A todo Estado debe corresponder una Nación, a toda Nación debe corresponder un Estado; por lo tanto, su fin es lograr una unidad nacional en un territorio determinado, donde domina un poder estatal.

2. El Estado nacional no obedece a ningún otro poder por encima de él; es absolutamente soberano.

Los dos rasgos del nacionalismo son: unidad, uniformidad, homogeneidad en lo interior, y exclusión en lo externo (Villoro, 1998, p. 14). Estas ideas parecen monopolizar el saber jurídico y su credo parece ser incuestionable en Latinoamérica. Seguidamente agrega:

\begin{abstract}
El Estado pluricultural supone, al lado del derecho a la igualdad, el derecho a la diferencia; igualdad de derecho en todos los individuos y comunidades a elegir y realizar su plan de vida que puede ser diferente en todos ellos. En lugar de la uniformidad de una forma de vida, de una cultura homogénea para todos, de un orden legal central, el respeto a la equidad entre todas las formas de vida. Este es el supuesto real de una verdadera tolerancia (Villoro, 1998, p. 30).
\end{abstract}

Nos movemos entonces en esta dicotomía de la supremacía del Estado nación y del surgimiento del Estado plurinacional. Si miramos al Estado nación como una ideología y no como una forma de organización interior del Estado, el asunto se hace más complejo, pues la imposición de esta perspectiva sería la eliminación de la diversidad a fin de preservar la "nación única". El peligro de la homogeneidad es el desconocimiento de las distintas culturas y la distitividad que eso acarrea. El Estado debe entonces encarar esta pluriculturalidad sin perder la unidad nacional.

Latinoamérica asiste hoy a la refundación del Estado. Esta refundación pasa por el reconocimiento de la plurinacionalidad. Esto implica un desafío radical al concepto de Estado moderno que se 
asienta en la idea de nación cívica -concebida como el conjunto de los habitantes (no necesariamente residentes) de un cierto espacio geopolítico a quienes el Estado reconoce el estatuto de ciudadanos- $y$, por lo tanto, en la idea de que en cada Estado sólo hay una nación: el Estado-nación. La plurinacionalidad es una demanda por el reconocimiento de otro concepto de nación, la nación concebida como pertenencia común a una etnia, cultura o religión (Boaventura, 2010, p. 81).

Entonces, es pertinente preguntarnos iqué implicaciones tiene el Estado pluricultural?, la respuesta que más se acerca a lo que pasa en nuestro contexto la da la profesora Catherine Walsh cuando afirma:

La designación constitucional de un Estado como Estado pluricultural y multiétnico, acontece cuando se pasa de la esfera de lucha de las culturas excluidas a convertirse en política del Estado. Es claro que en este paso, no sólo pierde algo de su sentido reivindicativo, sino que entra por el medio, una serie de intereses distintos. Por eso, varios autores advierten que atrás de las nuevas políticas latinoamericanas del reconocimiento e inclusión, juega una nueva lógica cultural del capitalismo global, una lógica que intenta controlar y armonizar la oposición con la pretensión de eventualmente integrar a los pueblos indígenas y negros dentro del mercado (Walsh, 2002).

$\mathrm{Y}$ reafirma la autora el hecho de que los reconocimientos constitucionales no existen aislados, sino que forman parte de un conjunto de políticas de tipo multiculturalista, tanto del Banco Mundial como de las empresas transnacionales. Los desafíos no son de poca monta, pues dejar el campo reivindicativo para reconocerse en el Estado como poder y permitir la pluralidad, que otrora se aclamó para las nuevas minorías, es una oportunidad de construir distintas racionalidades de la diversidad y de la diferencia, alejadas de las concepciones excluyentes y arribistas que marcaron la historia de nuestra América.
El Estado plurinacional y pluricultural no es una redundancia. Es la materialización de la inclusión, de lo distinto, de lo invisible, pero no para aplastar o pisotear lo no originario y ancestral, es por el contrario convivencia de distintos órdenes culturales y la posibilidad de construir un buen vivir entre todos los habitantes de un Estado que garantiza la plena realización del sujeto colectivo, así como de los intereses individuales.

La búsqueda es en últimas lo que denomina Boaventura de Sousa la "convivialidad", que no es otra cosa que una reconciliación orientada al futuro. Los agravios del pasado se han saldado de tal forma que se facilitan las sociabilidades que se fundamentan en intercambios tendencialmente iguales y en la autoridad compartida. Los diferentes universos jurídicos son tratados como visiones alternativas de futuro que, cuando entran en conflicto, aceptan un "modus vivendi" definido según reglas constitucionales consensuadas.

Es lo que denota claramente la Constitución boliviana cuando señala esta nueva perspectiva:

Son fines y funciones esenciales del Estado [...]: 1. Constituir una sociedad justa y armoniosa, cimentada en la descolonización, sin discriminación ni explotación, con plena justicia social, para consolidar las identidades plurinacionales (Constitución Política del Estado de Bolivia, 2009, capítulo segundo, art. 9).

\section{DE LA DIVERSIDAD A LA PLURINACIONALIDAD}

En noviembre de 2001 se adoptó por aclamación una Declaración Universal sobre la Diversidad Cultural con el objetivo de responder a los desafíos que plantea la mundialización en materia cultural. Esta declaración solemne considera por primera vez que "la diversidad cultural es, para el género humano, tan necesaria como la diversidad biológica para los organismos vivos". 
La diversidad cultural y su reconocimiento e inclusión tomó varios siglos en nuestra latitud, hecho que se asumió por lo impostergable de la realidad y de la propia lucha social y política de las minorías en nuestro continente. Varios autores se preguntan si este reconocimiento e inclusión pretende atacar las asimetrías y promover relaciones equitativas. Más bien, sólo añade la particularidad étnica a la matriz existente, sin buscar o promover una mayor transformación. Por ello la pregunta: ¿Qué implicaciones tiene en el Estado pluricultural la diversidad? La diversidad en un Estado pluricultural se convierte en la centralidad política y social, en expresión del "buen vivir". Sin duda, las organizaciones indígenas han luchado por Estados que expresen y valoren la diversidad cultural, al igual que garanticen el pleno ejercicio de los derechos humanos y colectivos de los pueblos, comunidades y nacionalidades que habitan estos territorios.

Para el constitucionalismo latinoamericano, la diversidad cultural implica un desafío aún mayor y de connotaciones propias. Bajo la presión de los movimientos indígenas y en un esfuerzo de legitimación que problematiza su indudable impronta neocolonial, varios Estados latinoamericanos han constitucionalizado, bajo fórmulas variables, el derecho a la diversidad cultural y a la identidad. Tal reconocimiento ha incluido expresiones culturales claves de los pueblos indígenas tales como sus idiomas, territorios y sistemas de autoridad y normativos (Grijalva, 2009, p. 391).

En la Constitución colombiana, por ejemplo, el artículo $7^{\circ}$ establece: "El Estado reconoce y protege la diversidad étnica y cultural de la Nación colombiana". Este artículo se ha desarrollado ampliamente gracias a la jurisprudencia de la Corte Constitucional en materia de pueblos indígenas, que ha permitido, entre otros aspectos, dilucidar la tensión clásica diversidad - unidad nacional.
En la Sentencia de tutela T-523ㄹ de 1997 , afirma el magistrado Carlos Gaviria:

[...] En especial, son claras las tensiones entre reconocimiento de grupos culturales con tradiciones, prácticas y ordenamientos jurídicos diversos y la consagración de derechos fundamentales con pretendida validez universal [...]. Mientras una mayoría los estima como presupuestos intangibles, necesarios para un entendimiento entre naciones, otros se oponen a la existencia de postulados supraculturales, como una manera de afirmar su diferencia, y porque de acuerdo con su cosmovisión no ven en ellos un presupuesto vinculante (Gaviria, 2002 p. 335).

Esta segunda tensión entre reconocimiento de grupos culturales y derechos fundamentales, es superada por las nuevas constituciones que son claras en establecer la subordinación de los órdenes jurídicos a la constitución y los derechos humanos, y de manera muy explícita las nuevas constituciones también establecen la relación unidad diversidad.

El artículo $3^{\circ}$ de la Constitución ecuatoriana, señala como deber primordial del Estado: "Fortalecer la unidad nacional en la diversidad".

Este deber primordial del Estado se convierte en orientación del Estado pluricultural y premisa básica para fortalecer el diálogo intercultural entre las instituciones estatales y las naciones o nacionalidades indígenas. Este reconocimiento, en efecto, es problemático ya que con el argumento de la unidad nacional se ha querido imponer la unidad cultural.

Diego Iturralde (2009) aclara porque la cultura nacional impide, en algunos casos, la pluriculturalidad en los siguientes términos:

3 Esta sentencia se titula "La solución constitucional a los conflictos entre el principio de diversidad étnica y otros principios de igual jerarquía". 
A la falacia de la cultura nacional se opone en la práctica la existencia de múltiples culturas desarrolladas por pueblos sometidos a la dominación colonial y a la explotación; pueblos que conforme luchan por retener o recuperar los medios para su supervivencia y forman una conciencia de su interés como productores y de identidad como sociedad van construyendo la clase del trabajo y se expresan como verdaderas nacionalidades, que disputan la legitimidad del estado. Es el caso de las nacionalidades indígenas y es la historia de la relación entre las facciones dominantes y los pueblos indios, desde el contacto colonial hasta nuestros días (Iturralde, 2009, p. 109).

El resultado de estas luchas se traduce en las Constituciones de Bolivia y Ecuador, que proclaman el Estado plurinacional y el buen vivir. Su materialización jurídica y práctica sin duda es la prueba del ejercicio pleno de la diversidad. Esto acarreará contradicciones y dificultades. Pero los pueblos y nacionalidades indígenas están conscientes de la oportunidad histórica de construir ese nuevo Estado y ese buen vivir en la diversidad, sin romper la unidad nacional.

El ex presidente de la Asamblea Constituyente de Ecuador, Alberto Acosta ${ }^{4}$, plantea en esta línea: La declaratoria del Estado plurinacional por parte de la Asamblea Constituyente en Montecristi, representa, por un lado, un acto de resarcimiento histórico para los pueblos y nacionalidades indígenas. Y por otro lado es simultáneamente una oportunidad para que nuestra sociedad aprenda de los otros, asumiendo un compromiso de convivencia democrática y equitativa, en el que la armonía debe ser la marca de las relaciones de los seres humanos entre sí, y de estos con la naturaleza.

Esta es entonces una oportunidad no sólo para los pueblos y nacionalidades indígenas, sino para

4 Ver al respecto El estado plurinacional, puerta para una sociedad democrática. A manera de prólogo en Plurinacionalidad democracia en la diversidad (2009). la sociedad en general de construir otra manera de asumir la diversidad cultural más allá de lo establecido por el orden normativo. Como afirma el dirigente indígena ecuatoriano Luis Macas: "no podemos tener un proyecto político sólo para los indios", estas son, entre otras, las implicaciones del Estado pluricultural.

\section{VIGENCIA DEL PLURALISMO EN ESTADOS PLURINACIONALES}

Bourdieu plantea que es necesaria una sociología impertinente para lograr tener una sociología pertinente. Por esto la pregunta: ies pertinente el pluralismo en el marco de un Estado pluricultural? De partida es necesario reconocer un pluralismo político, social y jurídico de nuevo calado; este pluralismo implica un replanteamiento de los órdenes políticos, sociales y legales donde estos coexisten, especialmente, en el marco del Estado plurinacional.

El Estado plurinacional demanda inexorablemente la pluralidad, pero una pluralidad de culturas que se reconocen mutuamente, donde una no se impone a la otra. Es decir, es la realización plena del pluralismo que se materializa en el Estado pluricultural.

Este Estado plurinacional tiene como premisa de su actuación la interculturalidad, entendiendo por ésta la necesidad de construir relaciones entre grupos, entre prácticas, lógicas y conocimientos distintos, con el propósito de confrontar y transformar las relaciones del poder (incluyendo las estructuras e instituciones de la sociedad) que han naturalizado las asimetrías sociales, la multi o pluriculturalidad simplemente como parte de la pluralidad étnico-cultural de la sociedad y del derecho a la diferencia. Esta nueva forma de acción institucional abre múltiples posibilidades a los países andinos de repensarse como sociedades incluyentes y democráticas. 
En virtud de estos avances alcanzados por los países que se proclaman como pluriculturales y plurinacionales, auscultemos la ley No. 027 del 6 de julio de 2010, Ley del Tribunal Constitucional Plurinacional de Bolivia, que nos permite empezar a revisar el camino que recorrerán las instituciones plurinacionales. El artículo $3^{\circ}$ de esta nueva Ley, señala los principios que rigen la justicia constitucional en los siguientes entre otros:

1. Plurinacionalidad. Es la existencia de naciones y pueblos indígena originario campesinos, comunidades interculturales $y$ afro bolivianas, bolivianas y bolivianos que en su conjunto constituyen el pueblo boliviano.

2. Pluralismo jurídico. Proclama la coexistencia de varios sistemas jurídicos en el marco del Estado plurinacional.

Podemos entender entonces, a partir de este marco legal, la plurinacionalidad como sinónimo de pluriculturalidad; es disiente el numeral primero del artículo $3^{\circ}$ cuando reconoce la existencia de naciones y pueblos que en su conjunto constituyen el pueblo boliviano. El numeral segundo es complementario del primero en tanto proclama la coexistencia de varios sistemas jurídicos en el Estado plurinacional.

El pluralismo jurídico, afirma el sociólogo francés J. P. Proudhon, es el resultado del pluralismo social. El pluralismo social es necesario como lo es el propio pluralismo jurídico. La coexistencia de órdenes jurídicos garantiza la armonía socio jurídica necesaria para la viabilidad de un Estado. Este pluralismo, como lo pluricultural, dan cuenta de lo propio frente a las otras culturas. El ejercicio del derecho propio permite la autonomía de los pueblos, su autodeterminación jurídica, pese a que en algunos países no se haya reconocido la jurisdicción indígena, y donde esto ha ocurrido, la mayoría de las veces se hace en condiciones de subordinación a un orden jurídico dominante.
Un pluralismo jurídico pluricultural y plurinacional es el que permite el ejercicio pleno de los sistemas jurídicos donde estos se desarrollan independiente y mutuamente subordinados, ambos sistemas, el occidental y el indígena, a la constitución y al interés general.

\section{¿CONSTITUCIONALISMO CULTURAL O INTERCULTURAL?}

Colombia inició en los noventa un constitucionalismo progresista en materia de derechos de los pueblos indígenas. Sus desarrollos se sustentaron mayoritariamente en varios artículos constitucionales, como el artículo $7^{\circ}$ o el $46^{\circ}$. Los desarrollos jurisprudenciales tienen como fundamento el reconocimiento cultural.

El reconocimiento del pluralismo y la igualdad de culturas en la Constitución colombiana, plantearon un problema que la Corte asume en la Sentencia T-254 de 1994, donde expone un criterio que podríamos considerar tradicional en la relación de Occidente con otras culturas jurídicas; $y$ en la Sentencia T-349 de 1996, elabora una reflexión acorde con presupuestos socio antropológicos y jurídicos que interpretan el sentido del pluralismo cultural orientado por la Constitución.

Estos elementos, entre otros, nos permiten aseverar la tendencia del constitucionalismo colombiano a ser culturalista por interpretación y por aplicación a la realidad y al contexto nacional. Vale la pena señalar que en estos años no ha llegado a la Corte Constitucional colombiana en calidad de miembro de esta corporación un indígena.

En el caso del Ecuador, la nueva Corte Constitucional sigue en parte los pasos de la Corte colombiana. Sin embargo, la nueva Corte, que cumple ya dos años sufrió transformaciones sustanciales. Prueba de ello es el fallo que sentó un importante precedente en Ecuador y nivel internacional, relacionado con la demanda de inconstitucionalidad 
presentada por las nacionalidades indígenas a la Ley de minería.

La Corte ecuatoriana declaró la inconstitucionalidad de algunos artículos de esa Ley, y ante la falta de normas relacionadas con la consulta previa a las comunidades, dictó algunas regulaciones de estricto cumplimiento. Se trató de un hecho inédito en Ecuador, pues se reconocen los derechos de los pueblos establecido desde 1986 en el Convenio 169 de la Organización Internacional del Trabajo (OIT), sobre pueblos indígenas y tribales.

Otra sentencias notables de este nuevo período fue redactada por la magistrada indígena Nina Pacari y se refiere a una acción por incumplimiento presentada por los representantes de la Universidad Intercultural de las Nacionalidades y Pueblos Indígenas (AMWTAY WASI) en contra del CONESUP (Consejo Nacional de Educación Superior). La Universidad presentó una propuesta para abrir tres programas en diferentes regiones del país que fue rehusada por el CONESUP con el argumento de que la Universidad tenía su sede en Quito y que allí debían ser impartidos sus programas. En su demanda a la Corte, la Universidad invocó que el CONESUP había considerado y tratado a la universidad indígena como una universidad convencional y que con eso violaba los derechos colectivos de los pueblos indígenas consagrados en la Constitución y en los tratados internacionales, particularmente, su derecho a establecer instituciones de educación en sus propios idiomas y en consonancia con sus métodos culturales de enseñanza y aprendizaje. La Corte decidió a favor de los demandantes con una argumentación de alto nivel jurídico y político-cultural centrada en dos ejes fundamentales: la diferencia jurídico-política y la diferencia epistemológica o cognitiva. Por un lado, las normas constitucionales e internacionales reconocen la especificidad cultural de la educación indígena y por eso sus métodos no pueden quedar sometidos a un criterio extraño a su realidad y cosmovisión. Por otro lado, el conocimiento es epistemológicamente distinto, ya que, al contrario del conocimiento científico occidental, no se produce en "centros" sino en las comunidades mismas:

\begin{abstract}
Bajo una cosmovisión completamente diferente de la convencional, en donde la persona va hasta un centro de estudios en busca de conocimiento, cuando, en las realidades de los pueblos indígenas, el conocimiento está en la naturaleza, en los mismos pueblos, en su entorno. En consecuencia, el centro de estudios debe trasladarse hasta aquellos lugares para recibir y nutrirse, juntamente con los mismos pueblos, de sus "saberes o conocimientos" (Caso No. 0027-09-AN, con sentencia de 9 de diciembre de 2009).
\end{abstract}

Esta sentencia se constituye en hoja de ruta para lo que debe ser una verdadera justicia intercultural.

En Bolivia, el Tribunal Constitucional en Sentencia Constitucional 0243/ 2010-R del 31 de mayo afirma lo siguiente:

\begin{abstract}
[...] tanto la jurisdicción indígena originaria campesina, como la ordinaria, están controladas por la justicia constitucional y, en definitiva, por el Tribunal Constitucional Plurinacional, órgano que debe controlar el respeto a los derechos y garantías fundamentales en ambas jurisdicciones, considerando los principios generales de la potestad de impartir justicia previstos en el art. 178 de la CPE, entre ellos, el pluralismo jurídico y la interculturalidad.
\end{abstract}

Conforme a ello, el Tribunal Constitucional Plurinacional se convierte en el órgano esencial para la consolidación del pluralismo y la interculturalidad en Bolivia. De ahí deriva la necesidad de su conformación plural, que en cierta medida garantizará el diálogo entre culturas, para permitir que las diferentes atribuciones del Tribunal Constitucional sean ejercidas en el marco de los principios antes anotados, lográndose bases, principios y consensos mínimos en un Estado plurinacional que sustenten una convivencia armónica entre las diferentes culturas. 
En efecto, el Tribunal Constitucional Plurinacional se convierte en el órgano esencial para la consolidación del pluralismo y la interculturalidad en Bolivia y esta sentencia es explicita en reconocer la necesidad de la conformación plural como garantía del interculturalismo. Esta sentencia es paradigmática en virtud de sus enunciados, pues ellos allanan el camino para la conformación pluralista del alto tribunal, que en efecto se constituye en referente de esta índole en el continente.

La nueva Constitución boliviana avanza, como ninguna, en el reconocimiento de la administración de justicia por parte de las autoridades de las comunidades, pueblos y nacionalidades indígenas y deja muy claro que las normas y procedimientos propios para la solución de sus conflictos internos, no podrán ser contrarios a la Constitución y a los derechos humanos reconocidos en instrumentos internacionales. Establece con esto la unidad nacional reconociendo la diversidad conforme lo establece al artículo 171 de la Constitución:

\begin{abstract}
Art. 171.- Las autoridades de las comunidades, pueblos y nacionalidades indígenas ejercerán funciones jurisdiccionales, con base en sus tradiciones ancestrales y su derecho propio, dentro de su ámbito territorial, con garantía de participación y decisión de las mujeres. Las autoridades aplicarán normas y procedimientos propios para la solución de sus conflictos internos, y que no sean contrarios a la Constitución y a los derechos humanos reconocidos en instrumentos internacionales. El Estado garantizará que las decisiones de la jurisdicción indígena sean respetadas por las instituciones y autoridades públicas. Dichas decisiones estarán sujetas al control de constitucionalidad. La ley establecerá los mecanismos de coordinación y cooperación entre la jurisdicción indígena y la jurisdicción ordinaria.
\end{abstract}

Es muy temprano para evaluar los alcances de este constitucionalismo y de la consagración constitucional de la pluriculturalidad y del pluralismo jurídico pleno, pero las decisiones hasta hora proferidas por el Tribunal Constitucional bolivia- no, dejan entre ver un camino todavía entre el culturalismo y la interculturalidad. Seguramente cuando los magistrados indígenas inicien sus funciones, conoceremos una justicia más próxima a la intercultural.

En Bolivia los magistrados indígenas que formaran parte del Tribunal Constitucional Plurinacional tendrán tres caminos que asumir: circunscribir su accionar meramente a revisar los asuntos de los pueblos indígenas en una suerte de segunda instancia o de tribunal de revisión de lo actuado por las autoridades indígenas, reduciendo su actuar a la mínima expresión. Sí ejercen sus funciones mirando sólo los temas de las minorías, desarroIlarán un constitucionalismo cultural un poco a la colombiana. Pero si la apuesta es desarrollar un constitucionalismo intercultural, tendrán que revisar el ejercicio amplio del pluralismo en Bolivia y opinar sobre todos los temas que lleguen a la corporación, tanto como los magistrados no indígenas que opinaran sobre los temas indígenas, al entender que las decisiones serán mediante.

Frente a las anteriores afirmaciones vale la pena recordar que existe la sala especializada del Tribunal Constitucional Plurinacional que conocerá adicional y exclusivamente las consultas de las autoridades indígenas originario campesinas sobre la aplicación de sus normas jurídicas a un caso concreto, según lo establece el artículo 32 de la ley 027. Esto conllevaría a la primera de las opciones si la tarea de los representantes de las nacionalidades indígenas realiza su actuar solo a través de esta sala.

Sin embargo, la ley señala como atribuciones jurisdiccionales de la Sala Plena del Tribunal Constitucional Plurinacional varias responsabilidades señaladas en los numerales 11 y 12 con respecto a los conflictos de competencia entre la jurisdicción indígena originario campesina y las jurisdicciones ordinaria y agroambiental (que se desarrolla posteriormente en el art 124 de la ley), así como las 
consultas de las autoridades indígena originario campesinas sobre la aplicación de sus normas jurídicas a un caso concreto (desarrollado en los art, 137-140 de la ley).

Esto acarreará que los casos de los numerales 11 y 12 pasen por la sala plena, en la cual se decidirá los conflictos de competencia así como las respectivas consultas con el grueso de miembros del Tribunal, situación que implicará decisiones en clave intercultural.

Los dos indígenas representantes en el Tribunal Constitucional Plurinacional son además garantes de la plurinacionalidad y de la pluriculturalidad, esto conlleva varias responsabilidades adicionales a estos magistrados, pero la principal será la de garantizar el ejercicio de la jurisdicción por parte de las autoridades indígenas originario campesinas de sus derechos colectivos. Sus decisiones serán un producto del entendimiento intercultural entre los miembros del Tribunal en materia de derechos indígenas, así como las decisiones de parte de los magistrados no indígenas.

Sumado a esto aparece la preocupación por las decisiones sustantivas finales en las correspondientes acciones de defensa que no se produzcan por la instancia de revisión, sino, mediante casación o anulación y devolución o reposición, por la jurisdicción indígena originario campesina. El Tribunal Constitucional Plurinacional habría así de auto restringirse al control procedimental de garantías en asuntos procedentes de la jurisdicciones indígenas. Esto es algo que habrá de plantearse en la práctica o quizás contemplarse en la Ley de Deslinde Jurisdiccional prevista por la Constitución (art. 192.III), pues la ya promulgada Ley del Tribunal Constitucional Plurinacional no considera la mencionada situación (Clavero, 2010). Múltiples situaciones pueden presentarse antes de que se promulgue el código de procedimiento constitucional, y algunas o muchas situaciones de los pueblos indígenas llegaran a la sala especializada donde se prohijara un nuevo constitucionalismo que establezca las bases del estado pluricultural.

En últimas compartimos plenamente lo planteado por el constitucionalista ecuatoriano, Agustín Grijalva, cuando afirma:

El constitucionalismo plurinacional no puede sino ser profundamente intercultural, puesto que a él le corresponde constituirse en el ámbito de relación igual y respetuosa de distintos pueblos y culturas a efectos de mantener las diferencias legítimas, eliminar o al menos disminuir las ilegitimas $y$ mantener la unidad como garantía de la diversidad (Grijalva, 2009, p. 391).

\section{CONCLUSIÓN: LAS ENCRUCIJADAS DEL NUEVO ESTADO}

Debemos recordar que la Constitución ecuatoriana del 2008 establece un Estado plurinacional e intercultural, a diferencia de la Constitución de 1998, la cual establecía un Estado pluricultural y multiétnico. El Constitucionalista Grijalva (2009, p. 391 ) aborda este tema en profundidad y señala:
El Ecuador, desde 1998 evidencia un de- sarrollo importante del reconocimiento de la diversidad cultural a nivel constitu- cional formal. Este desarrollo, empero, no se ha expresado de forma proporcional en las políticas públicas, la legislación y la jurisprudencia (Grijalva, 2009, p. 391).

Y agrega que "a pesar del amplio catálogo de derechos colectivos de los pueblos indígenas, no se llegó a dictar casi ninguna normativa legal al respecto". Plantea además que el Estado plurinacional no es o no debe reducirse a una Constitución que incluye un reconocimiento puramente culturalista, a veces solo formal, por parte de un Estado, en realidad instrumentalizado para el dominio de pueblos con culturas distintas, sino un sistema de foros de deliberación intercultural auténticamente democrático. 
Esto nos llevaría a una primera encrucijada entre un Estado radicalmente democrático y las ya conocidas democracias liberales representativas. Cabe entonces preguntarse si es definitivamente una premisa del Estado plurinacional su intensificación democrática, o es una exigencia para impedir su realización.

Conforme a lo ya planteado, se espera de un Estado plurinacional mayor inclusión y cero exclusión, ¿pero acaso es posible acabar definitivamente con las formas de exclusión y discriminación? Tal vez no, pero lo que sí garantiza la plurinacionalidad es mayor inclusión de la hasta ahora lograda por el Estado y las expresiones que de él conocemos.

La anterior Constitución ecuatoriana que se consideraba pluricultural y multiétnica no logró avanzar mucho en sus cometidos. La nueva Constitución y el orden político vigente enfrentan singulares dificultades en lo intercultural, dando cuenta de lo difícil que es lograr la plurinacionalidad e interculturalidad que se predica actualmente en el texto constitucional. Pese a la falta de gobernabilidad y los enfrentamientos entre el Gobierno y las organizaciones indígenas, subyace a la construcción del Estado plurinacional experimentar y consolidar nuevas formas de representación y de participación que garanticen la legitimidad requerida de esta nueva forma de Estado. Se está iniciando el proceso y se tiene el derecho a equivocarse $y$ corregir el rumbo cuantas veces sea necesario.

Boaventura (2010, p. 130) señala que lo que está en disputa no es solamente un conjunto más o menos innovador de políticas públicas, sino también, y sobre todo, un pacto político nuevo que además contiene una dimensión de cambio civilizatorio. En ese sentido, el pensamiento político de los cambios presupone el des-pensamiento político de todos los instrumentos teórico-analíticos que impidieron los cambios o los trivializaron. Los cambios pueden resumirse en tres conceptos transicionales: desmercantilizar, democratizar y descolonizar.
Para el presente análisis sólo miraremos las implicaciones de democratizar o lo que llama el propio Boaventura (demodiversidad) que no es otra cosa que buscar nuevas articulaciones entre la democracia representativa, democracia participativa y democracia comunitaria; y sobre todo extender los campos de deliberación democrática más allá del restringido campo político liberal que transforma la democracia política de isla democrática en un archipiélago de despotismos.

Si es posible encontrar estas articulaciones, la tarea de las instituciones plurinacionales es hallarlas y desarrollarlas conforme a la intensidad democrática existente. El Tribunal plurinacional es "per se" un ejercicio de demodiversidad. Por ello, las expectativas en su composición, como lo que de él emane y produzca, será parte de distintas cosmovisiones legales, que acercarán a Bolivia a un interculturalimo legal, que será expresión de la democratización del ejercicio jurídico constitucional.

El ejercicio autónomo de la administración de justicia por parte de los pueblos y nacionalidades, constituye lo que denomino derecho profano. Este derecho es la base para lograr una efectiva democratización de la justicia. Lo que hasta ahora se afirma por algunos detractores de estas justicias es la capacidad antidemocrática, individualista, clientelista y poco útil de las llamadas justicias indígenas y comunales (Ariza, 2010).

Sin embargo, está probada por varios trabajos la capacidad pacifista de estas justicias ${ }^{5}$ así como los logros que ofrece en materia de descongestión judicial, de acceso a la justicia y de cuanta política pública se inventan los reformistas legales.

5 Desde el trabajo pionero de Brandt, Hans-Jürgen (1990), En nombre de la paz comunal: un análisis de la justicia de paz en el Perú, $1^{\text {a }}$ ed., Lima: Centro de Investigaciones judiciales de la Corte Suprema de Justicia de la República y Fundación Friedrich Naumann. Los trabajos de Uprmny y otros, se sostiene "y verifica" el potencial pacifista de estas justicias. 
El auge de estas justicias se da por la confluencia de múltiples factores, pero el más destacado, sin duda alguna, es el déficit democrático en el sistema político. Sin embargo, se debe reconocer que no es suficiente para el nivel de conflictividad que enfrentan los Estados plurinacionales con una sola administración de justicia. Se requiere, por tanto, una administración intercultural de justicia. Esto plantea una encrucijada de orden estructural, pues no existen referentes para este proceso.

El cómo lograr un ejercicio democrático de la nueva justicia intercultural presenta desafíos de diferente índole. Tal vez el más complejo es la hibridación que se dará entre el derecho occidental y el derecho propio o ancestral, hecho que sucedió de manera impositiva. La diferencia ahora es que se hará de forma democrática. Recuperar el valor de la democracia comunitaria como base de la convivencia social permite un mayor grado de participación en todos los órdenes y hace de ellos un asunto público de todos y todas.

En últimas, una nueva concepción de lo público $y$ del interés general que sean formulas reales $y$ no meramente retórica legal. Lograr que Bolivia o Ecuador se constituyan en unos Estados unitarios de Estado social de derecho plurinacionales comunitarios, democráticos, interculturales, descentralizados y con autonomías, no será tarea fácil, pero con el saber y el conocimiento acumulado como plurinación, es posible imaginar otra sociedad e incluso otra democracia realmente intercultural, que nos permita de una buena vez salir de las actuales encrucijadas.

\section{REFERENCIAS}

Acosta, A. (2009). El Estado plurinacional, puerta para una sociedad democrática. A manera de prólogo en Plurinacionalidad Democracia en la diversidad. Quito.
Ariza, R. (2010). El derecho Profano. Bogotá: Universidad Externado de Colombia.

Boaventura, S. (2010). La refundación del Estado, perspectivas desde una epistemología del Sur. Lima: Instituto Internacional de Derechos y Sociedad.

Clavero, B. (2010). Tribunal constitucional entre Estado plurinacional y pueblos indígenas: un reto inédito en las Américas. Recuperado de [http:// clavero.derechosindigenas.org/wp-content/ uploads/2010/09/Bolivia TCPlurinacional-blog1. pdf].

Grijalva, A. (2009). El Estado plurinacional e intercultural en la Constitución ecuatoriana de 2008. En: Derechos ancestrales y justicia en contextos plurinacionales. Serie Justicia y derechos humanos. Neoconstitucionalismo y sociedad. Ecuador: Ministerio de Justicia y Derechos Humanos.

Chivi, I. (2009). Los desafíos de la justicia comunitaria (y bases para una "Ley de Deslinde Jurisdiccional"). La Paz: International Institute for Democracy and Electoral Assistance; El valor de la jurisdicción indígena originario campesina en Bolivia, en Aporte DPLF (Fundación para el Debido Proceso Legal).

Itrurralde, D. (2009). Nacionalidades indígenas y Estado nacional en Ecuador, en derechos colectivos hacia una efectiva comprensión y protección. Serie Justicia y derechos Humanos. Neoconstitucionalismo y Sociedad. Ecuador: Ministerio de Justicia y Derechos Humanos.

Villoro, L. (1998). Del Estado homogéneo al Estado plural (el aspecto político: la crisis del estadonación). En: Estado plural, pluralidad de culturas. México: UNAM/Paidós. 